\title{
Improvement of Carded Yarn Quality by Changing Ring Frame Break Draft for Different Short Fibre Index
}

\author{
Md. Riazul Hoque \\ Department of Textile Engineering, Mawlana Bhashani Science and \\ Technology University, Tangail-1902 \\ Md. Rokonuzzaman \\ Joykrisna Saha
}

Assistant Professor, Department of Textile Engineering, Mawlana Bhashani

Science and Technology University, Tangail-1902

Mohammed Farhad Mahmud Chowdhury

Lecturer, Department of Textile Engineering, Mawlana Bhashani Science and Technology University, Tangail-1902

Doi: 10.19044/esj.2017.v13n36p346 URL:http://dx.doi.org/10.19044/esj.2017.v13n36p346

\begin{abstract}
Three types of cotton fibers lot having short fiber index (SFI) 8.65, 9.45 and 11.00 were taken to perform the experiment. The break drafts (BD) in ring frame were set to $1.136,1.174$ and 1.211 to produce the sample yarn; $30^{\mathrm{S}} / 1$ carded knit yarn $(30 \mathrm{KK})$ and $34^{\mathrm{S}} / 1$ carded knit yarn $(34 \mathrm{KK})$. The objective of this study was to find out the impact of short fibers by changing ring frame break draft on yarn quality and spinning process performance. The yarn quality such as $\mathrm{CVm} \%$, thin places $(-50 \%) / \mathrm{km}(\mathrm{TN})$, thick places $(+50 \%) / \mathrm{km}(\mathrm{TK})$, neps $(+200 \%) / \mathrm{km}(\mathrm{NP})$, count-strength product (CSP) and yarn hairiness $(\mathrm{H})$ found satisfactory level for both yarn count in case of ring frame break draft 1.174 for low and high short fiber index. In this study, both physical and tensile properties of ring yarn were found better for ring frame break draft 1.174 of the three samples and quality deteriorates as SFI increases from 8.65 to 11.00 .
\end{abstract}

Keywords: Short fiber index, Break draft, Carded yarn, Cotton fiber, Yarn strength

\section{Introduction}

The proportion of short fibers has an extremely great influence on yarn quality, on personnel and on the machines. Unfortunately, the SFI has 
increased substantially in recent years in cotton available from many sources due to mechanical plucking and hard ginning. In the great majority of cases, the absolute short fiber proportion is specified today as the percentage of fibers shorter than $10-12.5 \mathrm{~mm}$ (Schenek. A, 1982), (Lord. E. 1961). Since the short fibers cannot be measured easily, this value is seldom really accurate (Klein, W. 1987). The fibers of under $4-5 \mathrm{~mm}$ will be lost in processing as waste and fly, fibers up to about $12-15 \mathrm{~mm}$ do not contribute to strength but only to fullness of the yarn and only those fibers above these lengths produce the other positive characteristics in the yarn (Klein, W. 1987). Short fibers generate due to intensive opening rendering the yarn uneven and weak (Istiaque. S. M. 2003). The task of the break draft in the first draft zone is simply to prepare the fiber strand for main draft in the second zone by breaking the frictional bond in roving; so that the main draft should be affected with fewer disturbances and smoothly. The range of break draft normally lies between 1.10 and 1.40 .

\section{Materials \& Methods}

The mean characteristics of cotton fibers tested at Uster ${ }^{\mathrm{TM}} \mathrm{HVI}$ Spectrum as illustrated in Table 01 having short fiber index 8.65, 9.75 and 11.00 were respectively processed in spinning machineries Ring frame (LR6/A, India). Then the rovings of SFI 8.65 were processed in a ring frame machine with $1.136,1.176$ and 1.212 break draft and produced $30 \mathrm{~S} / 1$ carded knit and $34^{\mathrm{S}} / 1$ carded knit yarn. After that the produced yarns were tested by Uster $^{\mathrm{TM}}$ evenness tester (UT 5) to observe CVm\%, thin places $(-50 \%) / \mathrm{km}$, thick places $(+50 \%) / \mathrm{km}$, neps $(+200 \%) / \mathrm{km}$, hairiness and yarn CSP by "Skein method' by lea strength tester. Similarly the rovings of short fiber index 9.75 and 11.00 were processed in a ring frame machine with 1.136, 1.176 and 1.212 break draft and produced $30^{\mathrm{S}} / 1$ carded knit and $34^{\mathrm{S}} / 1$ carded knit yarn to observe evenness and tensile properties.

Table 1: Fiber characteristics

\begin{tabular}{|c|c|}
\hline Parameter & Specification \\
\hline Cotton & CIS (Uzbekistan) \\
\hline Staple length & $28.7 \mathrm{~mm}$ \\
\hline Micronaire & 4.7 \\
\hline Strength & $29 \mathrm{gm} / \mathrm{tex}$ \\
\hline Uniformity index & 83.9 \\
\hline
\end{tabular}

\section{Results and Discussion}

Yarn evenness quality were observed for different SFI and break draft as shown in Table 2 and Figure 01. From Table 2, it was found that thick places $(+50 \%) / \mathrm{km}$ was lower break draft 1.174 compared to break draft 1.136 and 1.211 for low and high short fiber index. The number of thick 
places increases due to the high SFI. Since the short fibers can hardly be controlled in the draw boxes, it leads to the formation of thick places.

Thin places $(-50 \%) / \mathrm{km}$ also found lower in case of break draft 1.174 for low and high short fiber index. Actually, the number of thin places increases due to the high amount of short fibers, which leads to the formation of thin places.

Neps are thick places of very short length. Therefore, the number of neps can only slightly influence the yarn evenness. From Table 2 and Figure 01 , it was observed that neps $(+200 \%) / \mathrm{km}$ found also less for ring frame break draft 1.174 compared to ring frame break draft 1.136 and 1.211 for low and high short fiber index.

Table 2: Yarn Imperfection value for different SFI and break draft

\begin{tabular}{|c|c|c|c|c|c|c|}
\hline \multirow{2}{*}{ Parameters } & \multicolumn{2}{|c|}{ Short fiber index 8.65 } & \multicolumn{2}{c|}{ Short fiber index 9.45 } & \multicolumn{2}{c|}{ Short fiber index 11.00 } \\
\cline { 2 - 7 } & $30^{\mathrm{S}} / 1 \mathrm{KK}$ & $34^{\mathrm{S}} / 1 \mathrm{KK}$ & $30^{\mathrm{S}} / 1 \mathrm{KK}$ & $34^{\mathrm{S}} / 1 \mathrm{KK}$ & $30^{\mathrm{S}} / 1 \mathrm{KK}$ & $34^{\mathrm{S}} / 1 \mathrm{KK}$ \\
& $\mathrm{TN} / \mathrm{TK} / \mathrm{NP}$ & $\mathrm{TN} / \mathrm{TK} / \mathrm{NP}$ & $\mathrm{TN} / \mathrm{TK} / \mathrm{NP}$ & $\mathrm{TN} / \mathrm{TK} / \mathrm{NP}$ & TN/TK/NP & TN/TK/NP \\
\hline BD 1.136 & $1.5 / 55.5 / 169$ & $1.5 / 118.8 / 262.2$ & $2 / 99.3 / 284.5$ & $3.1 / 155.3 / 415$ & $3.5 / 99.3 / 295.7$ & $3 / 143.2 / 365$ \\
\hline BD 1.174 & $1 / 50.5 / 155.8$ & $1.5 / 103.5 / 245.3$ & $1.5 / 95.5 / 280.3$ & $3 / 145 / 400$ & $2 / 97.8 / 285$ & $2.5 / 138 / 350$ \\
\hline BD 1.211 & $1.5 / 58 / 184.8$ & $2.3 / 111 / 290$ & $2.2 / 118 / 284.5$ & $4.5 / 160.8 / 421.8$ & $3.5 / 105.5 / 304.5$ & $5 / 147 / 361$ \\
\hline
\end{tabular}

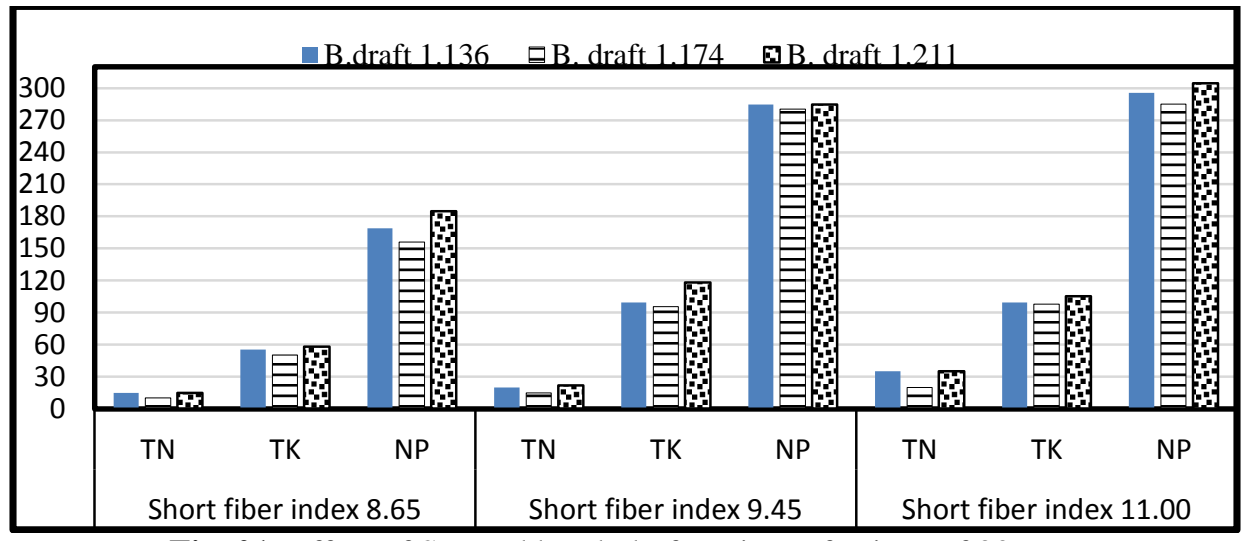

Fig. 01: Effect of SFI and break draft on imperfections of $30 \mathrm{KK}$.

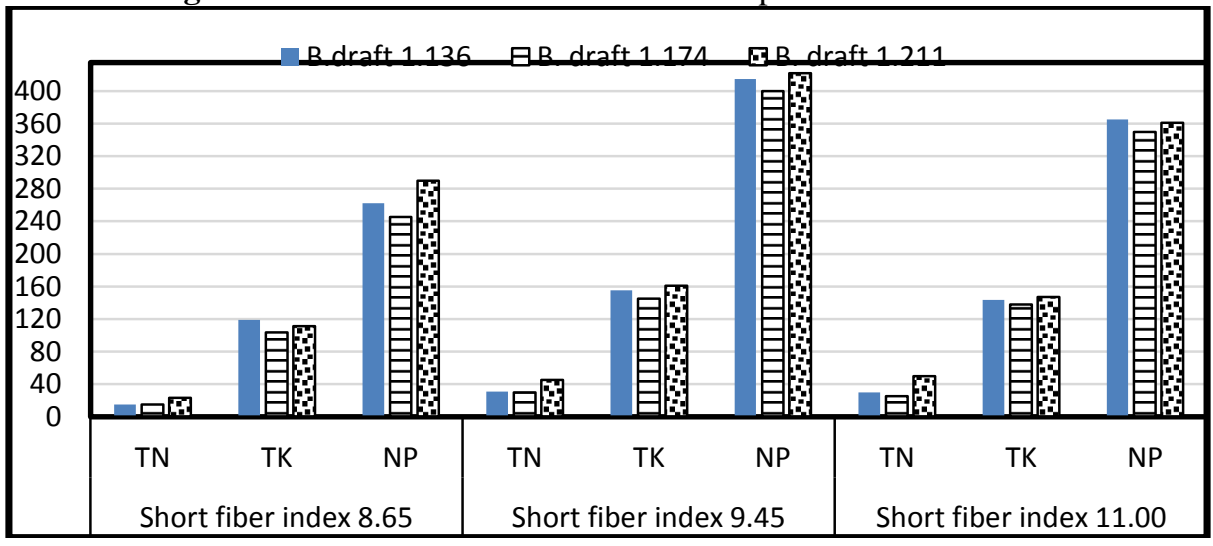

Fig. 02: Effect of SFI and break draft on imperfections of $34 \mathrm{KK}$. 
Table 3: $\mathrm{CVm}$ and $\mathrm{H}$ value for different SFI

\begin{tabular}{|c|c|c|c|c|c|c|}
\hline \multirow{2}{*}{ Parameters } & \multicolumn{2}{|c|}{ Short fiber index 8.65 } & \multicolumn{2}{|c|}{ Short fiber index 9.45 } & \multicolumn{2}{c|}{ Short fiber index 11.00} \\
\cline { 2 - 7 } & $\begin{array}{c}30^{\mathrm{S}} / 1 \mathrm{KK} \\
\mathrm{CVm} / \mathrm{H}\end{array}$ & $\begin{array}{c}34^{\mathrm{S}} / 1 \mathrm{KK} \\
\mathrm{CVm} / \mathrm{H}\end{array}$ & $\begin{array}{c}30^{\mathrm{S}} / 1 \mathrm{KK} \\
\mathrm{CVm} / \mathrm{H}\end{array}$ & $\begin{array}{c}34^{\mathrm{S}} / 1 \mathrm{KK} \\
\mathrm{CVm} / \mathrm{H}\end{array}$ & $\begin{array}{c}30^{\mathrm{S}} / 1 \mathrm{KK} \\
\mathrm{CVm} / \mathrm{H}\end{array}$ & $\begin{array}{c}34^{\mathrm{S}} / 1 \mathrm{KK} \\
\mathrm{CVm} / \mathrm{H}\end{array}$ \\
\hline BD 1.136 & $10.5 / 5.83$ & $11.07 / 5.50$ & $11.09 / 6.23$ & $11.44 / 5.68$ & $11.06 / 5.92$ & $11.49 / 5.83$ \\
\hline BD 1.174 & $10.45 / 5.25$ & $11.02 / 5.10$ & $11.03 / 5.52$ & $11.4 / 5.35$ & $11.01 / 5.65$ & $11.32 / 5.77$ \\
\hline BD 1.211 & $10.55 / 5.49$ & $11.18 / 5.17$ & $11.2 / 5.74$ & $11.55 / 5.65$ & $11.14 / 5.90$ & 11.575 .93 \\
\hline
\end{tabular}

$\mathrm{CVm} \%$ and hairiness value $(\mathrm{H})$ were observed for different count for different SFI and break draft as shown in Table 03 and Figure 03 and 04.From Table 3, it was observed that $\mathrm{CVm} \%$ found less for break draft 1.174 compared to break draft 1.136 and 1.211 for low and high short fiber index. Short fibers in cotton has the major responsibility for increasing yarn hairiness i.e. more short fibers in cotton generates more yarn hairiness and less short fibers in cotton generates less yarn hairiness which was shown in Table 3.

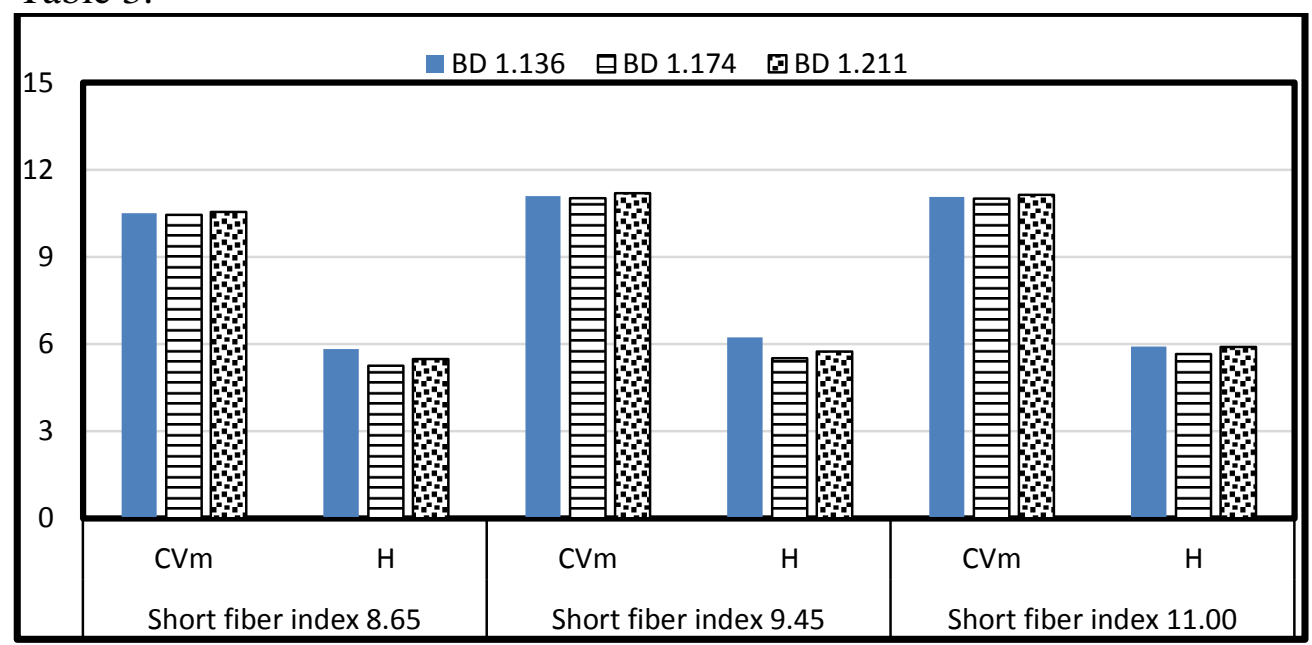

Fig. 03: Effect of SFI and break draft on $\mathrm{CVm} \%$ and $\mathrm{H}$ of $30 \mathrm{KK}$.

The effect of different SFI and break draft on yarn strength also observed. Yarn strength also depends on the amount of short fiber present in drafted strands. If amount of short fiber in the cotton more, yarn strength becomes low. Actually more short fiber deteriorates the yarn strength which was observed from Table 4 and Figure 05 


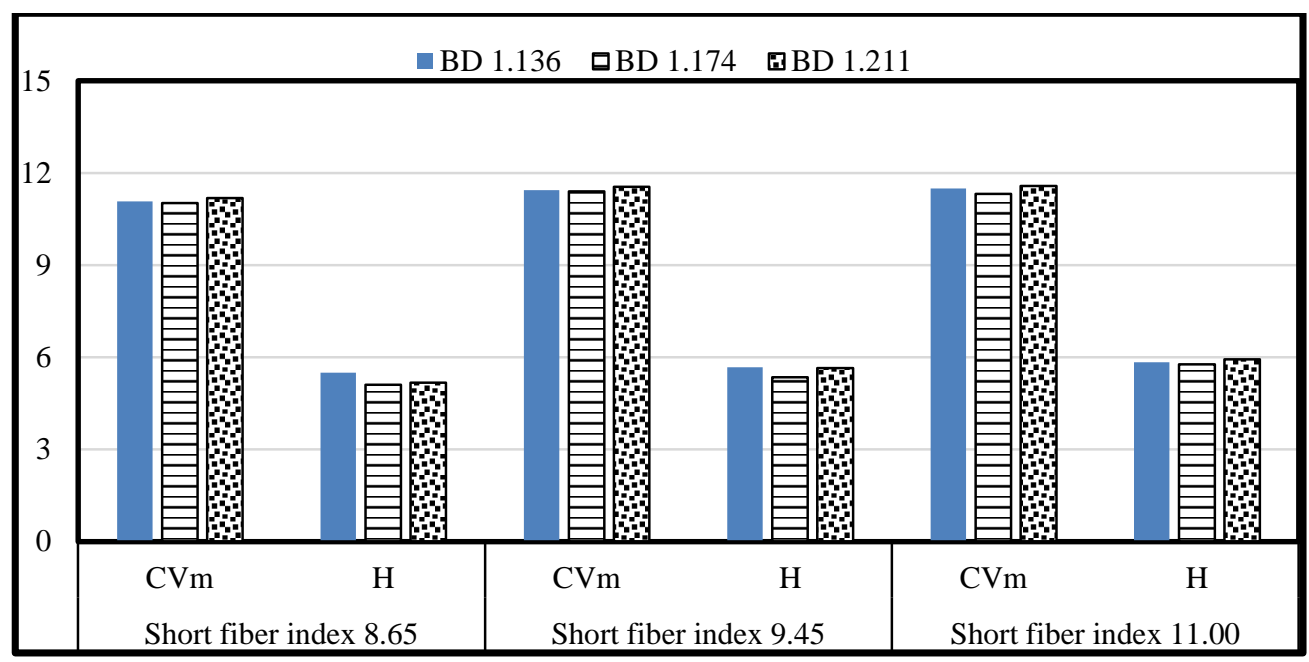

Fig. 04: Effect of SFI and break draft on $\mathrm{CVm} \%$ and $\mathrm{H}$ of $34 \mathrm{KK}$.

Table 4: CSP value of $30 \mathrm{KK}$ and $34 \mathrm{KK}$ for different SFI and break draft.

\begin{tabular}{|c|c|c|c|c|c|c|}
\hline \multirow{2}{*}{ Parameters } & \multicolumn{3}{|c|}{ Short fiber index 8.65} & \multicolumn{2}{c|}{ Short fiber index 9.45} & \multicolumn{2}{c|}{ Short fiber index 11.00} \\
\cline { 2 - 7 } & $30 \mathrm{~S} / 1 \mathrm{KK}$ & $34 \mathrm{~S} / 1 \mathrm{KK}$ & $30 \mathrm{~S} / 1 \mathrm{KK}$ & $34 \mathrm{~S} / 1 \mathrm{KK}$ & $30 \mathrm{~S} / 1 \mathrm{KK}$ & $34 \mathrm{~S} / 1 \mathrm{KK}$ \\
\hline BD 1.136 & 2410 & 2335 & 2310 & 2290 & 2205 & 2100 \\
\hline BD 1.174 & 2390 & 2345 & 2330 & 2275 & 2230 & 2140 \\
\hline BD 1.211 & 2400 & 2320 & 2335 & 2250 & 2210 & 2120 \\
\hline
\end{tabular}

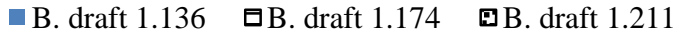

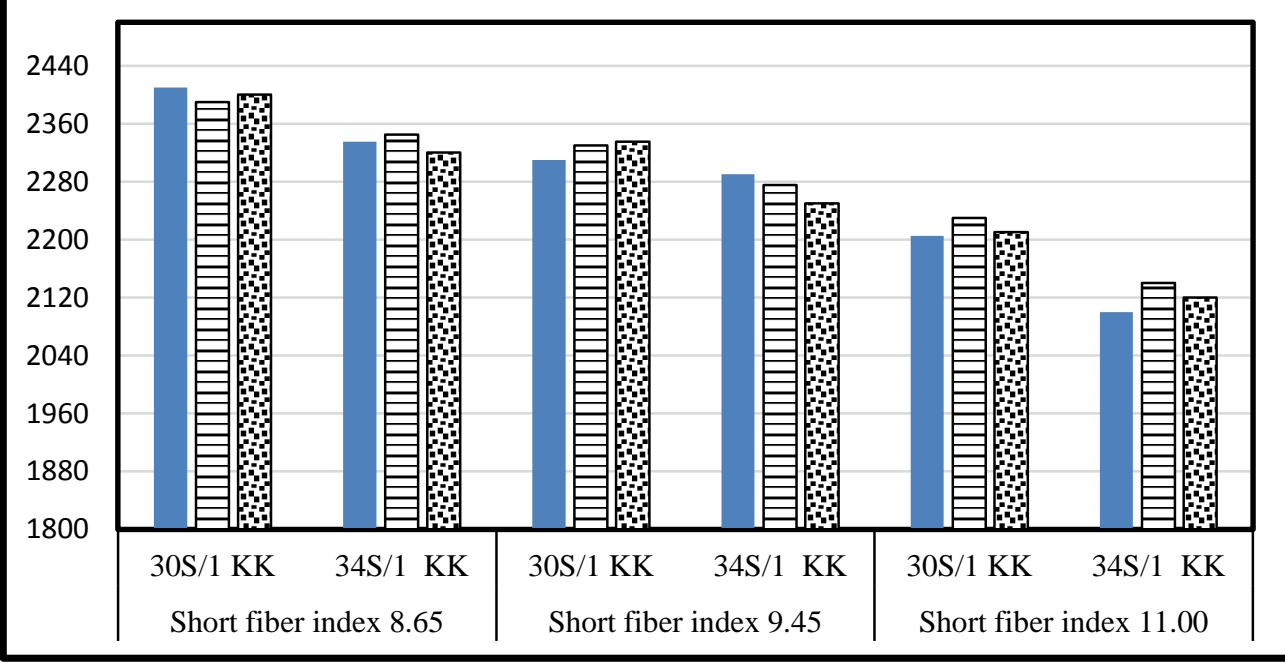

Fig. 05: Effect of SFI and break draft on CSP of $30 \mathrm{KK}$ and $34 \mathrm{KK}$. 


\section{Conclusion}

In this study it was found that Um\%, thin places $(-50 \%) / \mathrm{km}$, thick places $(+50 \%) / \mathrm{km}$, neps $(+200 \%) / \mathrm{km}$, strength and hairiness of $30 \mathrm{~S} / 1$ and $34 \mathrm{~S} / 1$ carded yarn less in respect of ring frame break draft 1.174 compared to ring frame break draft 1.136 and 1.211 for low and high short fiber index. Actually, yarn quality is almost influenced by short fiber in cotton fibers. If short fiber increases in cotton fibres, yarn quality deteriorates. This deteriorates can be minimized by different way. Proper selection of break draft in ring frame is one of them. So, it can be concluded that yarn quality for both yarn count found better in case of ring frame break draft 1.174 for low and high short fiber index.

\section{Acknowledgment}

The author is extremely grateful to the authorities of Viyellatex spinning mills Ltd., Maona, Sreepur, Gazipur for their co-operation and support to conduct this study in the factory.

\section{References:}

1. Schenek. A. (1982). Messmethooden zur bestimmung des Kurzfaseranteils in Rohbaumwolle, V 63 (pp. 551-554). Melliand Textilber.

2. Lord. E. (1961). The Characteristics of Raw Cotton (Manual of cotton Spinning, Volume II, Part 1), The Textile Institute and Butterworths, Manchester.

3. Klein. W. (1987). The Technology of Short-staple Spinning, Volume 1, The Textile Institute, Manchester.

4. Istiaque. S. M., Chaudhuri. S., \& Das. A. (2003). Influence of fibre openness on processibility of cotton and yarn quality: Part II- Effect of carding parameters, V 28, (pp. 405-410). Indian Journal of Textile Research. 